\title{
Association between Magnetic Resonance Imaging and the Result of Medial Branch Blocks
}

\author{
Stephan Klessinger ${ }^{1,2}$, Wolfgang Freund ${ }^{3}$ \\ ${ }^{1}$ Department of Neurosurgery, Nova Clinic, Biberach, Germany \\ ${ }^{2}$ Department of Neurosurgery, University of Ulm, Ulm, Germany \\ ${ }^{3}$ Department of Diagnostic and Interventional Radiology, University of Ulm, Ulm, Germany \\ Email: klessinger@nova-clinic.de, stephan.klessinger@uni-ulm.de,freund-ulm@t-online.de
}

How to cite this paper: Klessinger, S. and Freund, W. (2017) Association between Magnetic Resonance Imaging and the Result of Medial Branch Blocks. Pain Studies and Treatment, 5, 1-10.

http://dx.doi.org/10.4236/pst.2017.51001

Received: November 11, 2016

Accepted: January 8, 2017

Published: January 11, 2017

Copyright $\odot 2017$ by authors and Scientific Research Publishing Inc. This work is licensed under the Creative Commons Attribution International License (CC BY 4.0).

http://creativecommons.org/licenses/by/4.0/

(c) (i) Open Access

\begin{abstract}
The aim of this retrospective practice audit was to assess the correlation between painful zygapophysial joints and changes seen in magnetic resonance imaging (MRI). Patients with unilateral pain were tested with controlled medial branch blocks. The MRI scans of patients with a positive response were compared blinded with normal MRI scans. The dimensions of the joint were assessed and osteoarthritis was graded. Fifteen symptomatic patients and 15 asymptomatic patients were included and evaluated. Comparison of the joints showed that the maximum diameter of symptomatic joints was significantly larger, and the grading of osteoarthritis was significantly higher for symptomatic joints. No healthy patient was assigned a grade 3. Grades 2 and 3 were found significantly more often in symptomatic patients. Only one symptomatic joint was assigned grade 0 . Grade 0 was found significantly more often in asymptomatic patients. The presented MRI technique has limited value as a diagnostic test for lumbar zygapophysial joint pain. It is not possible to detect a single symptomatic joint. However, the osteoarthritis grading for the lumbar zygapophysial joints might be helpful for finding predictors for negative response if the results of the rating are grade zero. Therefore, unnecessary medial branch blocks might be avoided.
\end{abstract}

\section{Keywords}

Zygapophysial Joint, Facet Joint, Spine, Back Pain, Medial Branch Block, Magnet Resonance Imaging, Interventional Pain

\section{Introduction}

For a specific treatment of patients with low back pain the identification of the pain source is important. The zygapophysial joints are a possible pain source for which radiofrequency denervation exists as a specific treatment. A valid diagno- 
sis of lumbar zygapophysial joint pain provides the cardinal indication for treatment with medial branch neurotomy [1]. The identification of a zygapophysial joint as a pain source is difficult, because no aspect of the patient's history or physical examination characteristics can identify a joint as the cause of pain [2] [3]. Therefore, the most accepted method [1] for diagnosing zygapophysial joint pain is controlled medial branch blocks. They are used to test if the pain stems from the zygapophysial joint because the medial branch innervates it [1].

Target joints are usually identified by the pain pattern, local tenderness over the area, and provocation of pain with deep pressure. Though pain is the most common reason why patients undergo imaging of the spine [4], the evidence in the literature does not support the routine use of radiological imaging to diagnose zygapophysial joint pain [5]-[10]. The identification of a painful joint seems difficult, because the literature does not report any correlation between the clinical symptoms of low back pain and degenerative spinal changes on radiological imaging studies [11], including radiographs, magnetic resonance imaging (MRI), and computed tomography [8] [9]. Specifically, the association between degenerative changes in the lumbar facet joints and symptomatic low back pain remains unclear and is a subject of ongoing debate [5] [6] [7] [8]. The prevalence of abnormal zygapophysial joint changes in radiological imaging depends on the age of the study population, the imaging modality used, and the threshold of abnormality used. It would be very useful indeed to know imaging signs which are specific to zygapophysial joint pain.

The purpose of this study was to test the correlation between characteristics seen on MRI and the diagnosis of zygapophysial joint pain as determined by medial branch blocks. Symptomatic joints were compared with normal MRI images. It was assessed whether there is a correlation between the osteoarthritis grading of the zygapophysial joints and the identification of a joint as a pain source.

\section{Materials and Methods}

This study was designed as a retrospective practice audit. Patient data were drawn from an electronic medical record system. The therapeutic interventions were performed in a single ambulatory spine center by the first author.

MRI scans of patients with one-sided zygapophysial joint pain were compared with normal MRI scans of the lumbar spine. The symptomatic patients had low back pain on one side (left or right). The pain characteristics had to be suggestive of zygapophysial joint origin. The zygapophysial joint was identified as a pain source with one or two medial branch blocks at different appointments in the practice, each with about $1 \mathrm{ml}$ of bupivacaine $(0.25 \%)$ and $20 \mathrm{mg}$ triamcinolone. Injections were performed with fluoroscopic visualization using established techniques [1]. A positive response to the medial branch block required at least $50 \%$ pain relief. Index joints were identified by the pain pattern, local tenderness over the area and provocation of pain with deep pressure. The index level and the level above were tested at the same time. The severity of pain was evaluated 
using a numeric rating scale (NRS) ranging from zero to ten, before and within two weeks after the medial branch block. Patients were asked to call within 14 days. At this time, the pain intensity was evaluated. All but five patients additionally had a personal appointment in the practice within the next few days.

Included were all consecutive patients presenting with pain for a minimum of three months. Pain of appropriate quality was the primary indication for treatment. A current MRI of the lumbar spine was required. Excluded were patients with radicular pain (e.g., with a positive straight leg test) or radiculopathy (motor deficit or sensory changes), with a disc herniation consistent with the complaints, or discitis, spondylodiscitis, or an oncologic disease affecting the spine or a history of lumbar spine surgery. Patients with a lytic spondylolisthesis or higher-grade (Meyerding grades 2 to 4 [12]) degenerative spondylolisthesis were also excluded.

The control group consisted of normal MRI scans of the lumbar spine. These images were obtained for reasons other than pain.

MRI scans were reviewed independently of the interventions. The examiner was blinded to any information about the patient, especially weather the MRI scans belonged to a symptomatic patient or to a patient in the control group. In all MRI scans the levels L4/5 and L5/S1 on the left and right side were evaluated. The maximal dimension of the joints on transversal slices, including possible osteophytes, and the grading (Table 1) of osteoarthritis of the zygapophysial joints (existence of osteophytes, hypertrophy of the articular processes, subarticular bone erosions) was assessed. With the radiological features described above a classification with the grading system described by Weishaupt et al. [13] [14] was possible. The MRIs had been performed prior to this study by different radiologists.

The Fisher Exact Test was used to compare values of patients with positive and negative response to treatment. Welch's t-test [15] was used to test the hypothesis that two populations had equal means. $\mathrm{P}<0.05$ was set as the threshold for interpreting the results as significant.

\section{Results}

Between March 2014 and September 2014, 36 consecutive patients with lumbar

Table 1. Criteria for grading osteoarthritis of the zygapophysial joints (adapted from [13] [14]).

\begin{tabular}{cl}
\hline Grade & \multicolumn{1}{c}{ Criteria } \\
\hline 0 & $\begin{array}{l}\text { Normal facet joint space }(2-4 \mathrm{~mm} \text { width }) \\
\text { Narrowing of the facet joint space }(<2 \mathrm{~mm}) \text { and/or small osteophytes and/or mild } \\
\text { hypertrophy of the articular process } \\
2\end{array}$ \\
$\begin{array}{l}\text { Narrowing of the facet joint space and/or moderate osteophytes and/or moderate } \\
\text { hypertrophy of the articular process and/or mild subarticular bone erosions }\end{array}$ \\
$\begin{array}{l}\text { Narrowing of the facet joint space and/or large osteophytes and/or severe } \\
\text { hypertrophy of the articular process and/or severe subarticular bone erosions } \\
\text { and/or subchondral cysts }\end{array}$
\end{tabular}


pain met the inclusion criteria. Eleven patients were lost to follow-up. Of the remaining 25 patients 15 patients showed a pain reduction of a minimum of $50 \%$ after the medial branch blocks. These patients were included in this study as the symptomatic group. In most of them (66.7\%) controlled medial branch blocks were performed; the other five patients did not agree to a second medial branch block because of the pain reduction after the first treatment. The mean age of the patients was 53 years. The symptomatic level was L5/S1 in ten (66.7\%) cases and L4/5 in five cases (33.3\%). The left side was painful in seven patients (46.7\%) and the right side in eight patients (53.3\%). Three patients (20.0\%) had a pain history of three to six months, five patients (33.3\%) between 7 and 12 months and seven patients (46.6\%) of more than 12 months. The data are shown in Table 2. The mean age of the 15 patients in the control group was 38 years.

Figure 1 shows examples from the evaluation of the magnetic resonance images. In one patient the slices of the level L5/S1 were missing. Therefore, 118 joints were analyzed by the blinded reader (15 symptomatic patients plus $15 \mathrm{pa}$ tients from the control group, level L4/5 and L5/S1, left and right side). No significant difference was found in any parameter comparing left and right side results. The mean range of the maximum dimension of the joints was $22 \mathrm{~mm}$. The following grading for osteoarthritis with the criteria from Table 1 was obtained: mean 0.9; grade 0: 43 joints (36.4\%); grade 1: 50 joints (42.4\%); grade 2: 19 joints (16.1\%); grade 3: 6 joints (5.1\%). These results are shown in Table 3.

The main objective was to compare the symptomatic joints with the control group (Table 4). Fifteen patients with unilateral back pain were included. In five patients the level L4/5 was identified as painful, and in 10 patients the level L5/S1 was the pain source. Therefore, five painful L4/5 joints were compared with 30 asymptomatic joints from the same level of the control group and 10 symptomatic L5/S1 joints with 30 joints of the same level from the control group. The

Table 2. Characteristics of the symptomatic patients.

\begin{tabular}{|c|c|c|}
\hline & \multicolumn{2}{|c|}{ Patients with low back pain } \\
\hline & $\mathrm{n}$ & $\%$ \\
\hline $\mathrm{n}$ & 15 & 100.0 \\
\hline Men & 8 & 53.3 \\
\hline Women & 7 & 46.7 \\
\hline \multicolumn{3}{|l|}{ Level } \\
\hline $\mathrm{L} 4 / 5$ & 5 & 33.3 \\
\hline $\mathrm{L} 5 / \mathrm{S} 1$ & 10 & 66.7 \\
\hline \multicolumn{3}{|l|}{ Side } \\
\hline left & 7 & 46.7 \\
\hline right & 8 & 53.3 \\
\hline \multicolumn{3}{|l|}{ Pain history } \\
\hline $3-6$ months & 3 & 20.0 \\
\hline $7-12$ months & 5 & 33.3 \\
\hline$>12$ months & 7 & 46.6 \\
\hline
\end{tabular}




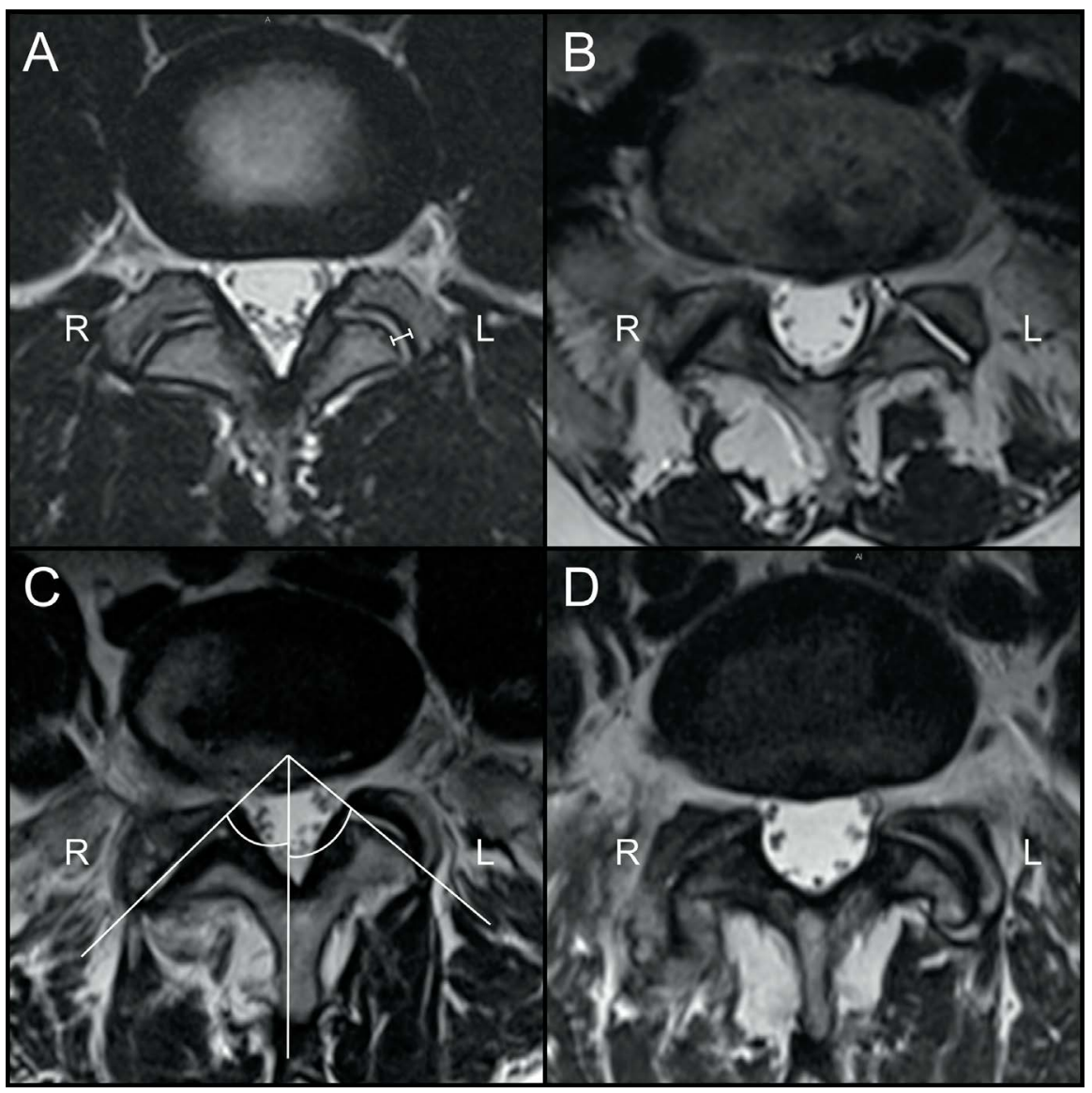

Figure 1. Axial T2 magnetic resonance imaging examples from patients included in this study; (A) Level L4/5. Patient from control group without back pain. Grading for both joints was grade 0; (B) Level L5/S1. This level was symptomatic on the right side. Grading for the joints was grade 1 for the right side and grade 0 for the left side. Different signals of the joint gap on the right and left side are recognizable; (C) Level L5/S1. This level was symptomatic on the right side. Grading for the joints was grade 2 for the right side and grade 0 for the left side; (D) Level L5/S1. This level was symptomatic on the right side. Grading for the joints was grade 3 for the right side and grade 2 for the left side. Different dimensions of the left and the right joint on transversal slices, including possible osteophytes are recognizable. L: left, R: right.

Table 3. Parameters of all analyzed joints.

\begin{tabular}{|c|c|c|c|}
\hline & & \multicolumn{2}{|c|}{ All analyzed joints } \\
\hline & & $\mathrm{n} /$ mean & $\%$ \\
\hline \multicolumn{2}{|c|}{$\mathrm{n}$} & 118 & 100.0 \\
\hline \multicolumn{2}{|c|}{ Max. dimensions (mean) } & $22 \mathrm{~mm}$ & \\
\hline \multirow[t]{4}{*}{ Grading } & 0 & 43 & 36.4 \\
\hline & 1 & 50 & 42.4 \\
\hline & 2 & 19 & 16.1 \\
\hline & 3 & 6 & 5.1 \\
\hline
\end{tabular}


Table 4. Significant differences between symptomatic joints and the control group.

\begin{tabular}{|c|c|c|c|c|}
\hline & & $\begin{array}{l}\text { Asymptomatic } \\
\text { joints }\end{array}$ & Symptomatic joints & Significance \\
\hline \multicolumn{5}{|c|}{ All joints } \\
\hline \multicolumn{2}{|l|}{$\mathrm{n}$} & 60 & 15 & \\
\hline \multicolumn{2}{|c|}{ Max. dimension (mean) } & $20.4 \pm 1.8 \mathrm{~mm}$ & $25.3 \pm 4.1 \mathrm{~mm}$ & $\mathrm{P}<0.05$ \\
\hline \multicolumn{2}{|c|}{ Grading (mean) } & $0.6 \pm 0.6$ & $1.5 \pm 0.8$ & $\mathrm{P}<0.05$ \\
\hline \multirow[t]{2}{*}{ Grade } & 0 & 29 & 1 & $P=0.003$ \\
\hline & $2+3$ & 5 & 7 & $P=0.015$ \\
\hline \multicolumn{5}{|c|}{$\mathrm{L} 4 / 5$} \\
\hline \multicolumn{2}{|l|}{$\mathrm{n}$} & 30 & 5 & \\
\hline \multicolumn{2}{|c|}{ Max. dimension (mean) } & $20.5 \pm 1.9 \mathrm{~mm}$ & $24.8 \pm 4.6 \mathrm{~mm}$ & $\mathrm{P}>0.05$ \\
\hline \multicolumn{2}{|c|}{ Grading (mean) } & $0.5 \pm 0.6$ & $1.6 \pm 1.1$ & $\mathrm{P}>0.05$ \\
\hline \multirow[t]{2}{*}{ Grade } & 0 & 16 & 1 & $\mathrm{P}=0.34$ \\
\hline & $2+3$ & 1 & 3 & $P=0.006$ \\
\hline \multicolumn{5}{|c|}{$\mathrm{L} 5 / \mathrm{S} 1$} \\
\hline \multicolumn{2}{|l|}{$\mathrm{n}$} & 30 & 10 & \\
\hline \multicolumn{2}{|c|}{ Max dimension (mean) } & $20.3 \pm 1.8 \mathrm{~mm}$ & $25.6 \pm 4.1 \mathrm{~mm}$ & $\mathrm{P}<0.05$ \\
\hline \multicolumn{2}{|c|}{ Grading (mean) } & $0.7 \pm 0.7$ & $1.5 \pm 0.7$ & $\mathrm{P}<0.05$ \\
\hline \multirow[t]{2}{*}{ Grade } & 0 & 13 & 0 & $P=0.018$ \\
\hline & $2+3$ & 4 & 4 & $\mathrm{P}=0.09$ \\
\hline
\end{tabular}

maximal dimension of the joints on transversal slices, including possible osteophytes, was significantly larger in all symptomatic joints (mean $25.3 \pm 4.1 \mathrm{~mm}$ ) compared with the control group (mean $20.4 \pm 1.8 \mathrm{~mm}),|\mathrm{t}|=4.49,(\alpha 1=$ $0.05) t(14)=1.76)$. The difference was also significant at the level L5/S1 (mean $25.6 \pm 4.1 \mathrm{~mm}$ versus $20.3 \pm 1.8 \mathrm{~mm}),|\mathrm{t}|=3.95,(\alpha 1=0.05) \mathrm{t}(9)=1.81)$. At L4/5 the dimension of the symptomatic joints was slightly larger (mean $24.8 \pm 4.6$ $\mathrm{mm}$ versus $21.5 \pm 1.9 \mathrm{~mm}),(|\mathrm{t}|=1.60,(\alpha 1=0.05) \mathrm{t}(4)=2.13)$, not significant $)$. Another significant difference between symptomatic joints and the control group concerns the grading of osteoarthritis. The mean grading was significantly higher in all symptomatic joints $(1.5 \pm 0.8)$ compared with asymptomatic joints $(0.6 \pm 0.6),|\mathrm{t}|=3.00,(\alpha 1=0.05) \mathrm{t}(18)=1.73))$. The difference was also significant at the level L5/S1 (mean $1.5 \pm 0.7$ versus $0.7 \pm 0.7),|t|=3.10,(\alpha 1=0.05) t(15)=$ 1.75). At L4/5 the grading of the symptomatic joints was also higher but not sig- 
nificant (mean $1.6 \pm 1.1$ versus $0.5 \pm 0.6),(|t|=2.12,(\alpha 1=0.05) t(4)=2.13))$. No patient in the control group was rated grade 3 . Joints graded 2 or 3 were found significantly more often in symptomatic patients (seven) compared with asymptomatic patients (five); $\mathrm{P}=0.015$ (sensitivity $47 \%$, specificity $92 \%$ ). The likelihood of a joint grade 2 or 3 being symptomatic is $58 \%$ (positive predictive value). A joint grade 2 or 3 will be nearly 6 times more likely symptomatic than a joint grade 0 or 1 (positive likelihood ratio 5.88). Accordingly, only one symptomatic joint was rated grade 0 . Joints with grade 0 were found significantly more often in asymptomatic patients (29) compared with symptomatic patients (one); $\mathrm{P}=$ 0.003 . The probability of a joint rated grade 0 being asymptomatic is $97 \%$ (negative predictive value). The negative likelihood ratio is only 0.14 . This means the probability to find a symptomatic joint grade 0 is very low.

When analyzing the MRI scans the examiner tried to figure out the symptomatic joint. The MRI scans of 26 patients (86.7\%) were identified correctly regarding symptomatic patient or control group (sensitivity 0.87 , specificity 0.87 , odds ratio 42.3). However, to specify the correct side and level was difficult. Only in six of the 15 symptomatic patients $(40.0 \%)$, the correct joint (left or right and L4/5 or L5/S1) was identified.

\section{Discussion}

This retrospective study investigated if routine MRI scans could identify symptomatic zygapophysial joints. The identification of the painful joint was successful in only $40 \%$. The measurement of the maximum diameter and the grading system for classifying osteoarthritis of the joint showed significant differences between symptomatic and asymptomatic joints. The probability that a joint rated grade 0 is asymptomatic is $97 \%$. This information is useful for the selection of joints to be tested with medial branch blocks. Joints with no osteoarthritis (grade 0 ) do not need to be tested with medial branch blocks.

It would be useful to have a simple classification system for evaluating zygapophysial joints in MRI, especially if the results indicate whether the pain arises from the joints and which joints should be treated. Most grading systems relate to degeneration. To a radiologist, degeneration can mean formation of osteophytes, decrease of joint space, subchondral sclerosis, or reduced signal intensity in MRI [4]. Thanks to its more precise demonstration of bony details [16] [17] [18], CT is superior for the evaluation of zygapophysial joints [19]. However, MRI is the diagnostic method of choice for the painful lumbar spine. Therefore, a grading system for MRI was chosen as a basis for this study. In a recent review of existing grading systems [14], only one grading system for the degeneration of the zygapophysial joints using MR was recommended [13]. This grading system of Weishaupt et al. [13] is shown in Table 1. If this grading system is used, there is moderate to good agreement between MR imaging and CT in the assessment of lumbar zygapophysial joint osteoarthritis [13].

Although this study showed larger diameter and higher grades of osteoarthritis in symptomatic joints, the grading system used in this study together with the 
other parameters is not suitable for identifying single symptomatic joints. Other studies found no increased osteoarthrosis in symptomatic patients. A large population study using plain radiography [20] and a smaller one using computed tomography (CT) [21] found osteoarthrosis to be equally prevalent in individuals with no pain as in patients with back pain. Similar negative results can be found in a previous CT study [8] and in a radiographic study [22]. Neither used an asymptomatic control group, and intra-articular injections were performed instead of medial branch blocks. A recent study comparing MRI scans of patients with positive and negative response to medial branch blocks found worse osteoarthritis in symptomatic patients, but the difference from asymptomatic patients was not significant [23]. Studies of older adults [24] [25] demonstrated that the presence of degenerative facet pathology in older adults is ubiquitous, but higher radiographic severity scores were associated with the presence of low back pain. Pneumaticos et al. [26] reported that patients with a SPECT prior to therapeutic infiltration of the zygapophysial joints had better pain scores one month after injection. Furthermore, the number of joints treated with injection decreased by up to two-thirds compared with the suggestions of the referring physician. However, a recent randomized controlled trial only found a modest correlation between SPECT/CT scan findings and the results of diagnostic infiltration of the rami mediales [27].

Several studies confirm that the prevalence of osteoarthritis of lumbar zygapophysial joints increases with age [4] [20] [21] [24] [25] [28], irrespective of pain [21] [28]. It is claimed that degenerative changes in the lumbar zygapophysial joints are often normal age changes [4]. In this study the mean age of the control group was younger (38 years) than the mean age of the symptomatic patients (53 years). Therefore, it cannot be ruled out that part of the differences in the grading of the joints is owed to age effects.

This study is a retrospective investigation with patients from a daily practice setting. A selection bias might have been introduced because of the necessity of an MRI. The reasons, why the referring doctor prescribed an MRI were not taken into account. Images with contrast were not available. Other limitations of the study are the small sample size and the difference in age between the two groups. An advantage is the use of MRI instead of CT because MRI is the diagnostic method of choice in patients with low back pain. Controlled medial branch blocks offer the best available diagnostic confidence.

\section{Conclusion}

It must be concluded that the presented MRI technique cannot positively predict the effect of the medial branch block. It therefore has limited value as a diagnostic test for lumbar zygapophysial joint pain. It is not possible to detect a single symptomatic joint. However, the osteoarthritis grading for the lumbar zygapophysial joints might be helpful for finding predictors for negative response if the results of the rating are grade zero. Therefore, unnecessary medial branch blocks might be avoided. Our results support the initiation of prospective trials 
with more patients and controlled medial branch blocks.

\section{References}

[1] International Spine Intervention Society (2013) Lumbar Medial Branch Blocks. In: Bogduk, N., Ed., Practice Guidelines for Spinal Diagnostic and Treatment Procedures, 2nd Edition, International Spine Intervention Society, San Francisco, 559600.

[2] Hancock, M.J., Maher, C.G., Latimer, J., Spindler, M.F., McAuley, J.H., Laslett, M. and Bogduk, N. (2007) Systematic Review of Tests to Identify the Disc, SIJ or Facet Joint as the Source of Low Back Pain. European Spine Journal, 16, 1539-1550. https://doi.org/10.1007/s00586-007-0391-1

[3] van Kleef, M., Vanelderen, P., Cohen, S.P., Lataster, A., Van Zundert, J. and Mekhail, N. (2010) 12. Pain Originating from the Lumbar Facet Joints. Pain Practice, 10, 459-469. https://doi.org/10.1111/j.1533-2500.2010.00393.x

[4] Bogduk, N. (2012) Degenerative Joint Disease of the Spine. Radiologic Clinics of North America, 50, 613-628. https://doi.org/10.1016/j.rcl.2012.04.012

[5] Badgley, C.E. (1941) The Articular Facets in Relation to Low-Back Pain and Sciatic Radiation. Journal of Bone and Joint Surgery, 23, 481-496.

[6] Nachemson, A.L. (1992) Newest Knowledge of Low-Back Pain: A Critical Look. Clinical Orthopaedics and Related Research, 179, 8-20. https://doi.org/10.1097/00003086-199206000-00003

[7] Schwarzer, A.C., Aprill, C.N., Derby, R., Fortin, J., Kine, G. and Bogduk, N. (1994) Clinical Features of Patients with Pain Stemming from the Lumbar Zygapophyseal Joints. Is the Lumbar Facet Syndrome a Clinical Entity? Spine, 10, 1132-1137. https://doi.org/10.1097/00007632-199405001-00006

[8] Schwarzer, A.C., Wang, S.C., O’Driscoll, D., Harrington, T., Bogduk, N. and Laurent, R. (1995) The Ability of Computed Tomography to Identify a Painful Zygoapophyseal Joint in Patients with Chronic Low Back Pain. Spine, 20, 907-912. https://doi.org/10.1097/00007632-199504150-00005

[9] Selby, D.K. and Paris, S.V. (1981) Anatomy of Facet Joints and Its Correlation with Low Back Pain. Contemporary Orthopaedics, 312, 1097-1103.

[10] Lehman, V.T., Murphy, R.C., Kaufmann, T.J., Diehn, F.E., Murthy, N.S., Wald, J.T., Thielen, K.R., Amrami, K.K., Morris, J.M. and Maus, T.P. (2014) Frequency of Discordance between Facet Joint Activity on Technetium Tc99m Methylene Diphosphonate SPECT/CT and Selection for Percutaneous Treatment at a Large Multispecialty Institution. American Journal of Neuroradiology, 35, 609-614. https://doi.org/10.3174/ajnr.A3731

[11] Raastad, J., Reiman, M., Coeytaux, R., Ledbetter, L. and Goode, A.P. (2015) The Association between Lumbar Spine Radiographic Features and Low Back Pain: A Systematic Review and Meta-Analysis. Seminars in Arthritis and Rheumatism, 44, 571-585. https://doi.org/10.1016/j.semarthrit.2014.10.006

[12] Meyerding, H.W. (1932) Spondyloptosis. Surgery, Gynecology \& Obstetrics, 54, 371-377.

[13] Weishaupt, D., Zanetti, M., Boos, N. and Hodler, J. (1999) MR Imaging and CT in Osteoarthritis of the Lumbar Facet Joints. Skeletal Radiology, 28, 215-219. https://doi.org/10.1007/s002560050503

[14] Kettler, A. and Wilke, H.J. (2006) Review of Existing Grading Systems for Cervical and Lumbar Disc and Facet Joint Degeneration. European Spine Journal, 15, 705718. https://doi.org/10.1007/s00586-005-0954-y 
[15] Portney, L.G. and Watkins, M.P. (2009) Foundations of Clinical Research: Applications to Practice. 3rd Edition, Prentice Hall, Upper Saddle River.

[16] Pathria, M., Sartoris, D.J. and Resnick, D. (1987) Osteoarthritis of the Facet Joints: Accuracy of Oblique Radiographic Assessment. Radiology, 164, 227-230. https://doi.org/10.1148/radiology.164.1.3588910

[17] Carrera, G.F., Houghton, V.M., Syvertsen A. and Williams A.L. (1980) Computed Tomography of the Facet Joints. Radiology, 134, 145-148. https://doi.org/10.1148/radiology.134.1.7350594

[18] Raskin, S.P. (1981) Degenerative Changes of the Lumbar Spine: Assessment by Computed Tomography. Orthopedics, 4, 186-195.

[19] Houghton, V. (1995) Imaging Techniques in Intraspinal Diseases. In: Resnick, D., Ed., Diagnosis of Bone and Joint Disorders, Saunders, Philadelphia, 237-276.

[20] Magora, A. and Schwartz, A. (1976) Relation between the Low Back Pain Syndrome and X-Ray Findings. 1. Degenerative Osteoarthritis. Scandinavian Journal of Rehabilitation Medicine, 8, 115-125.

[21] Kalichman, L., Li, L., Kim, D.H., Guermazi, A., Berkin, V., O’Donnell, C.J., Hoffmann, U., Cole, R. and Hunter, D.J. (2008) Facet Joint Osteoarthritis and Low Back Pain in the Community-Based Population. Spine, 33, 2560-2565. https://doi.org/10.1097/BRS.0b013e318184ef95

[22] Revel, M.E., Listrat, V.M., Chevalier, X.J., Dougados, M., N’guyen, M.P., Vallee, C., Wybier, M., Gires, F. and Amor, B. (1992) Facet Joint Block for Low Back Pain: Identifying Predictors of a Good Response. Archives of Physical Medicine and Rehabilitation, 73, 824-828.

[23] Klessinger, S., Halatsch, M.E. and Freund, W. (2015) Retrospective Magnetic Resonance Imaging Evaluation in Patients with Zygapophysial Joint Pain. Journal of Spine \& Neurosurgery, 4, 3.

[24] Hicks, G.E., Morone, N. and Weiner, D.K. (2009) Degenerative Lumbar Disc and Facet Disease in Older Adults: Prevalence and Clinical Correlates. Spine, 34, 13011306. https://doi.org/10.1097/BRS.0b013e3181a18263

[25] Suri, P., Hunter, D.J., Rainville, J., Guermazi, A. and Katz, J.N. (2013) Presence and Extent of Severe Facet Joint Osteoarthritis Are Associated with Back Pain in Older Adults. Osteoarthritis and Cartilage, 21, 1199-1206. https://doi.org/10.1016/j.joca.2013.05.013

[26] Pneumaticos, S.G., Chatziioannou, S.N., Hipp, J.A., Moore, W.H. and Esses, S.I. (2006) Low Back Pain: Prediction of Short-Term Outcome of Facet Joint Injection with Bone Scintigraphy. Radiology, 238, 693-698. https://doi.org/10.1148/radiol.2382041930

[27] Freiermuth, D., Kretzschmar, M., Bilecen, D., Schaeren, S., Jacob, A.L., Aeschbach, A. and Ruppen, W. (2015) Correlation of (99m) Tc-DPD SPECT/CT Scan Findings and Diagnostic Blockades of Lumbar Medial Branches in Patients with Unspecific Low Back Pain in a Randomized-Controlled Trial. Pain Medicine, 16, 1916-1922. https://doi.org/10.1111/pme.12841

[28] Ko, S., Vaccaro, A.R., Lee, S., Lee, J. and Chang, H. (2014) The Prevalence of Lumbar Spine Facet Joint Osteoarthritis and Its Association with Low Back Pain in Selected Korean Populations. Clinics in Orthopedic Surgery, 6, 385-391.

https://doi.org/10.4055/cios.2014.6.4.385 
Submit or recommend next manuscript to SCIRP and we will provide best service for you:

Accepting pre-submission inquiries through Email, Facebook, LinkedIn, Twitter, etc. A wide selection of journals (inclusive of 9 subjects, more than 200 journals)

Providing 24-hour high-quality service

User-friendly online submission system

Fair and swift peer-review system

Efficient typesetting and proofreading procedure

Display of the result of downloads and visits, as well as the number of cited articles Maximum dissemination of your research work

Submit your manuscript at: http://papersubmission.scirp.org/

Or contact pst@scirp.org 